\title{
Evaluation of thermal and vibration sensation in diabetic neuropathy
}

\author{
R. J.C. Guy, C. A.Clark, P. N. Malcolm and P.J. Watkins \\ Diabetic Department, King's College Hospital, London, UK
}

\begin{abstract}
Summary. Sensory evaluation of diabetic neuropathy was undertaken by a new technique for assessment of thermal sensitivity. The method is simple and reproducible, and the mean normal value of the lateral border of the foot was $6.0^{\circ} \mathrm{C}$ (3.6-9. ${ }^{\circ} \mathrm{C}, 95 \%$ confidence limits). Four groups of patients with diabetic neuropathy were examined: 22 with neuropathic ulcers and/or Charcot joints (groups 1 and 2); all showed severe abnormalities (range $10.8->30^{\circ} \mathrm{C}$ ), frequently more than three times the upper limit of normal. In contrast thermal sensitivity in 15 patients with painful neuropathy (group 4) varied from normal to grossly abnormal (range $3.9->30^{\circ} \mathrm{C}$ ) confirming this form of neuropathy as a distinct entity. The majority of those 10 patients with autonomic neuropathy alone (group 3) had abnormal thermal sensitivity (range 6.4-
\end{abstract}

$>30^{\circ} \mathrm{C}$ ). Comparison of thermal sensitivity (a small fibre modality) with vibration perception threshold (a large fibre modality) showed that thermal sensitivity is sometimes selectively affected, especially in those with painful neuropathy, suggesting that the small fibres are more vulnerable in diabetes. Frequent involvement of the hands confirms the "stocking and glove" distribution of diabetic neuropathy. We conclude that impairment of thermal sensivity is the rule in symptomatic diabetic neuropathy and its assessment provides a simple quantitive measurement suitable for long-term studies of its natural history.

Key words: Diabetes mellitus, neuropathy, thermal sensation, vibration perception threshold.
Diabetic neuropathies include a variety of distinct disorders sometimes affecting individual nerves or nerve roots, but most commonly occurring as a distal symmetrical polyneuropathy chiefly involving the feet. Symmetrical polyneuropathies themselves are predominantly sensory, but different nerve fibre types are not uniformly affected.

Evaluation of neuropathy is generally undertaken by electrophysiological measurements. The decrease in motor nerve conduction velocity is well documented, but is relatively little affected in diabetic subjects and correlates poorly with the clinical findings $[1,2]$. Sensory evaluation should be of greater importance in a neuropathy which is predominantly sensory and studies have shown that conduction velocity is diminished, sensory amplitude potentials reduced and spinal somatosensory conduction slowed early in diabetic neuropathy, reflecting loss of distal myelinated sensory axons [3-5]. The function of small unmyelinated fibres, which carry autonomic signals and awareness of pain and temperature sensation, is not reflected in any of the routine electrophysiological tests.

Sensory defects are relatively difficult to quantitate and may require considerable laboratory sophistication
[6]. The only sensory modality which has been extensively measured in diabetic neuropathy is vibration perception thresholds (a large myelinated fibre modality) [7] and this test is often used to define groups of neuropathic patients. Even with this test however, there has only been one attempt to correlate the observed deficit with clinical findings, namely neuropathic ulceration [8].

The aim of the present investigation was to evaluate thermal sensitivity (a small fibre modality) [7], using a relatively new technique, in clinically defined groups of patients with diabetic neuropathy. We intended to demonstrate, not only the severity of the defect in the different clinical categories, but also to compare the observations with vibration perception threshold and discover whether small and large fibres are affected together or independently. The extent of the abnormalities was also assessed in the hands as well as in the feet.

\section{Subjects and methods}

\section{Subjects}

The following groups of patients with various manifestations of diabetic neuropathy were studied; all were $<55$ years of age (Table 1 ). 
Table 1. Clinical details of subjects studied

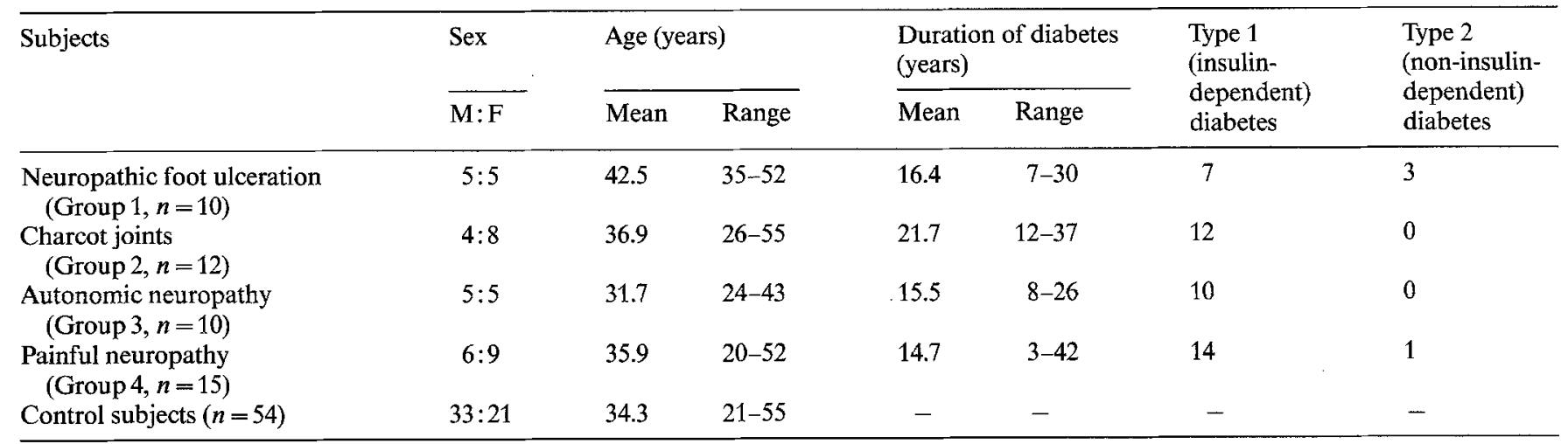

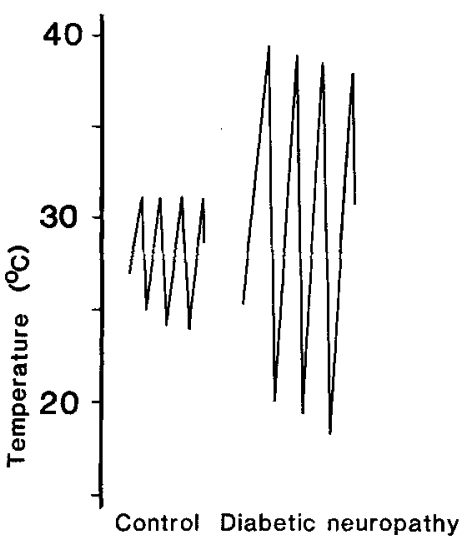

Fig. 1. Chart recording warm and cool sensory thermal thresholds in a control and a diabetic neuropathic subject tested at the lateral border of the foot. As soon as warmth was perceived, the subject pressed a switch, the stimulating surface was cooled and the subject pressed the switch again as soon as the stimulator was felt to be cool. This procedure was continued for $60-120 \mathrm{~s}$

Group 1 ( $n=10$; five men, five women): patients with neuropathic foot ulceration, defined as painless penetrating ulceration with absent ankle jerks and no evidence of ischaemia. Foot pulses were readily palpable in all cases.

Group 2 ( $n=12$; four men, eight women): patients with a Charcot's joint, defined as a fracture of bone with subsequent disorganisation of joint surfaces leading to bony deformity. Absent ankle jerks and good foot pulses were recorded in all cases.

Group 3 ( $n=10$; five men, five women): patients with an autonomic neuropathy were defined as those with a heart rate variability of $<10$ beats $/$ min (mean 3.7, range $0-7.2$ beats $/ \mathrm{min}$ ), and an absence of features of either group 1 or 2 . Of the 10 patients, all had symptomatic autonomic neuropathy, seven having two or more characteristic features. Diarrhoea from autonomic neuropathy was present in seven, postural hypotension (systolic blood pressure fall $\geqslant 30 \mathrm{mmHg}$ on standing) in five, gustatory sweating in four, delayed bladder emptying in three and gastroparesis in two. In addition all the males were impotent.

Group 4 ( $n=15$; six men, nine women): patients with neuropathic pain, defined as tingling paraesthesiae with burning pain, with or without intermittent, sharp, searing, shooting or stabbing pain originating in the feet. This was associated with contact discomfort and insomnia with a varying degree of severity of somatic neuropathy from negligible to profound [2].
Control subjects: Fifty-four healthy, non-diabetic subjects ( 33 men, 21 women), taking no medications and matched for sex and age, were studied.

All subjects gave informed consent and the study was approved by the hospital ethical committee.

Methods: All tests were conducted in the same room in quiet circumstances, with an ambient temperature between 18 and $21^{\circ} \mathrm{C}$. Subjects were allowed to adjust to the surroundings for $5 \mathrm{~min}$ and tests were always performed by one of three observers.

Thermal sensation: Thermal sensation was measured using a Marstock stimulator (Somedic, Stockholm, Sweden $[9,10]$ based on the Peltier principle that metal elements are heated or cooled, depending on the direction of flow of electric current. The rate of change of temperature of the plate over the range $15-45^{\circ} \mathrm{C}$ was $1{ }^{\circ} \mathrm{C} / \mathrm{s}$, which has been found to be suitable [9]. The plate was placed at the site being tested, a current of 3 amps was delivered to the plates and the subject was asked to press a switch as soon as the plate was felt to be either warm or cool. Once the switch was pressed, the direction of the current and therefore the direction of the temperature change was reversed. If the plate was initially heated, the switch was pressed when the plate was felt to be warm; the plate would then start to cool and the switch was pressed again when this sensation was appreciated. An illustrative recording is shown in Figure 1.

The temperature of the plate was measured by a thermocouple and displayed on a chart recorder. The plate measured $25 \times 50 \mathrm{~mm}$ and its back was thermally buffered by water circulating at $30^{\circ} \mathrm{C}$.

Temperature discrimination was tested on the palmar aspect of the index finger, the thenar eminence, the lateral border of the foot beneath the lateral malleolus and the plantar aspect of the big toe on the dominant side. In addition, 35 control subjects were studied on their non-dominant side and tests were performed twice in 18 control subjects and 18 diabetic subjects within one month. Following an explanation of the procedure and a trial test, recordings were made at each site for $60-120 \mathrm{~s}$. Once a stable recording was obtained, the differences between the warm and cold thresholds of five measurements were used to give a mean difference for thermal discrimination.

Skin temperature. Skin temperature was measured at the dominant big toe and index finger in 45 of the control and 43 of the diabetic subjects using a Thermalert TH-6D thermometer and a BT-1 probe (Bailey Instruments, Saddle Brook, New Jersey, USA).

Vibration sensation. Vibration sensation was measured using a handheld biothesiometer (Biomedical Instruments, Newbury, Ohio, USA). Vibration perception threshold was measured on the palmar aspect of the distal phalanx of the dominant index finger and the tip of the dominant big toe. In 35 control subjects the non-dominant side was also studied. The threshold was taken as the mean of three recordings after the test had been explained and demonstrated. The intensity of the vibratory stimulus was increased by increasing the voltage to the stimulator and results were expressed on an arbitrary scale in "volts". 


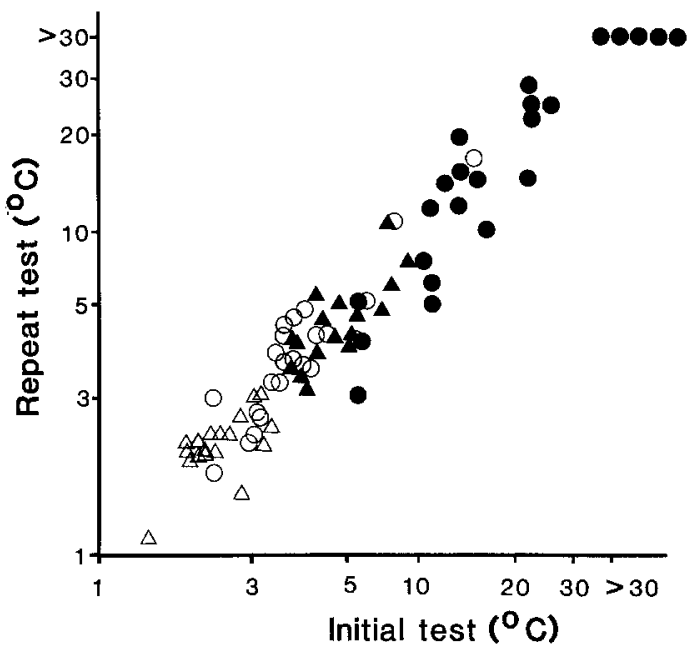

Fig. 2. Temperature sensation results performed twice on the same individuals, one month apart. There was no significant difference between all first and second readings considered together or when groups were analysed separately (normal or neuropathic hands, neuropathic feet) though the second readings on normal feet were slightly lower than the first $(0.05>p>0.01)$. $\Delta$ Normal hands $(n=18)$, correlation coefficient $\mathrm{r}=0.69, \mathrm{p}<0.01$; Oneuropathic hands $(\mathrm{n}=23)$, correlation coefficient $r=0.91, p<0.01 ; \Delta$ normal feet $(n=17)$, correlation coefficient $r=0.79, p<0.01$; neuropathic feet $(n=18)$, correlation coefficient $r=0.89, p<0.01$

Autonomic function tests. Autonomic function was assessed by the heart rate variability test at six breaths/min using a Lectromed rate meter, MX2P amplifier and MX212 chart recorder (Lectromed, St. Ouen, Jersey, Channel Islands). Abnormal values are $<10$ beats $/$ min, borderline values $10-12$ beats $/ \mathrm{min}$ [11].

\section{Statistical analysis}

Since thermal and vibration results were skewed to the right, all data were $\log _{10}$ transformed to normalise the distribution. Statistical analysis was performed using the Mann-Whitney U test and Spearman's rank correlation. For the reproducibility of the Method a correlation coefficient was used, excluding those results beyond the range of the tests. Results are expressed as mean and range of $95 \%$ confidence intervals. For neuropathic subjects above the limit of the tests, the maximum result was used (Figs. 3B and 5B). Non-paired Student's t-test was used to compare the results in different age groups.

\section{Results}

\section{Thermal sensation}

The thenar eminence of the hand proved to be more satisfactory than the index finger and was therefore used for all the investigations. The mean thermal sensitivity for the control subjects was $2.6^{\circ} \mathrm{C}\left(1.5-4.5^{\circ} \mathrm{C}\right)$ at the thenar eminence compared with $4.2^{\circ} \mathrm{C}\left(2.4-7.4^{\circ} \mathrm{C}\right)$ at the index finger. When the 54 control subjects were divided according to age into two equal groups (age range 21-34 and $35-55$ years), mean thermal sensitivity at the thenar eminence was found to be $2.4^{\circ} \mathrm{C}\left(1.5-4.0^{\circ} \mathrm{C}\right)$ in the younger group and $2.8^{\circ} \mathrm{C}\left(1.6-4.8^{\circ} \mathrm{C}\right)$ in the older group; these results were significantly different $(p<0.05)$ indicating a slight decrease in thermal sensitivity with age.
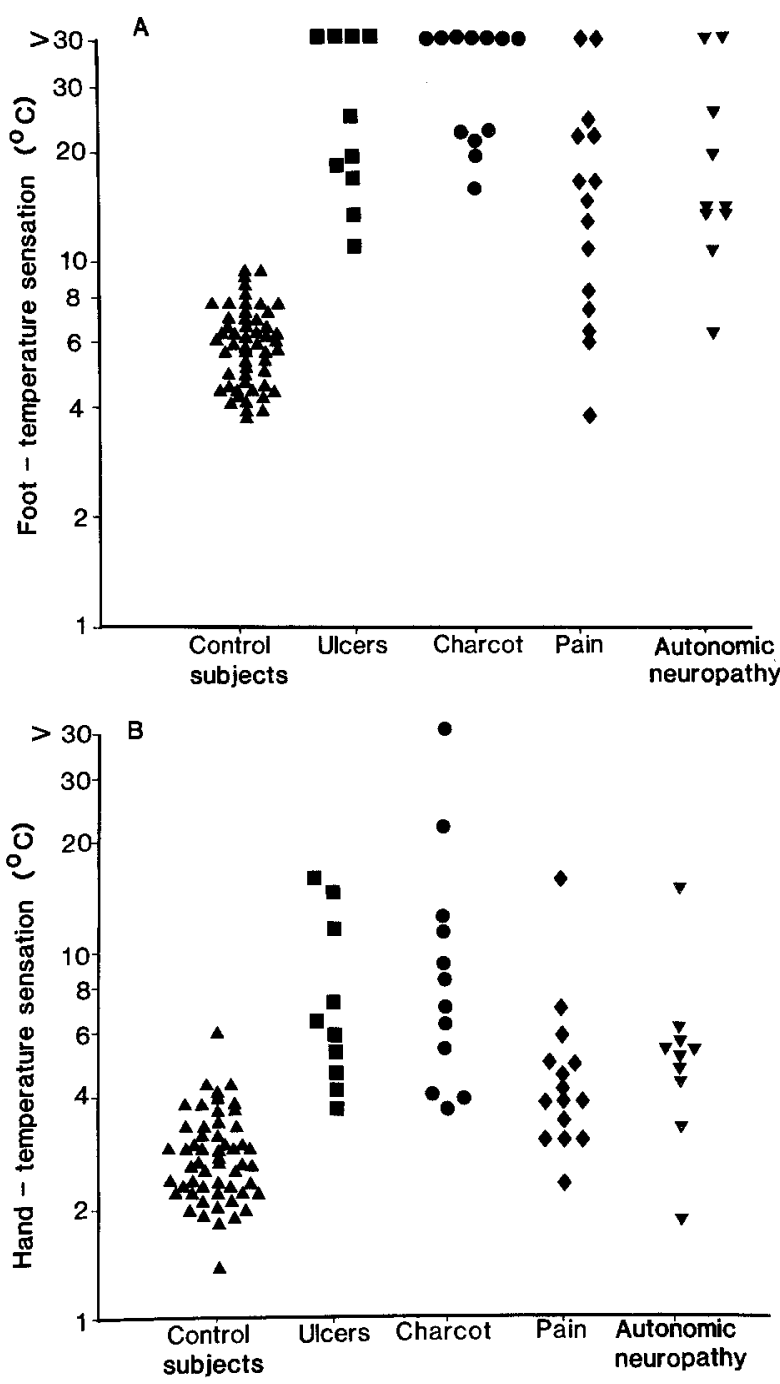

Fig.3. A Foot temperature sensation in non-diabetic control subjects and four groups of patients with neuropathy. All groups with neuropathy were significantly different from control subjects $(p<0.001$ in each case). (Mean levels and ranges are not shown because many of the results were beyond the limits of the test). B Hand temperature sensation. Controls, mean $2.6^{\circ} \mathrm{C} \quad\left(1.5-4.5^{\circ} \mathrm{C}\right)$; ulcers, $6.7^{\circ} \mathrm{C}$ $\left(2.4-18.9^{\circ} \mathrm{C}\right)$; Charcots, $8.0^{\circ} \mathrm{C}\left(2.1-30.0^{\circ} \mathrm{C}\right)$; painful neuropathy, $10.4^{\circ} \mathrm{C}\left(1.7-10.4^{\circ} \mathrm{C}\right)$; autonomic neuropathy, $4.9^{\circ} \mathrm{C}\left(1.7-13.6^{\circ} \mathrm{C}\right)$. All neuropathic groups were significantly different from control subjects $(p<0.001$ in each case)

Thermal sensitivity of the foot was less than that of the hand and on the lateral aspect of the foot was $6.0^{\circ} \mathrm{C}$ $\left(3.6-9.8^{\circ} \mathrm{C}\right)$. This was a more satisfactory area for testing the foot than the big toe. The result for the big toe was $8.9^{\circ} \mathrm{C}\left(5.2-15.1^{\circ} \mathrm{C}\right)$. At the lateral foot there was a small but not significant decrease in sensitivity with age, the mean thermal sensation being $5.7^{\circ} \mathrm{C}\left(3.7-8.7^{\circ} \mathrm{C}\right)$ in the age range $21-34$ years compared with $6.2^{\circ} \mathrm{C}$ $\left(3.6-10.8^{\circ} \mathrm{C}\right.$ ) in the older group (age range $35-55$ years).

The responses were symmetrical in the control subjects in the dominant and non-dominant sides both in the hands and feet. The results were as follows: thenar eminence $(n=34)$ dominant: $2.8^{\circ} \mathrm{C}\left(1.7-4.7^{\circ} \mathrm{C}\right)$; nondominant: $2.8^{\circ} \mathrm{C}\left(1.5-5.2^{\circ} \mathrm{C}\right)$; lateral foot $(n=35)$ dom- 


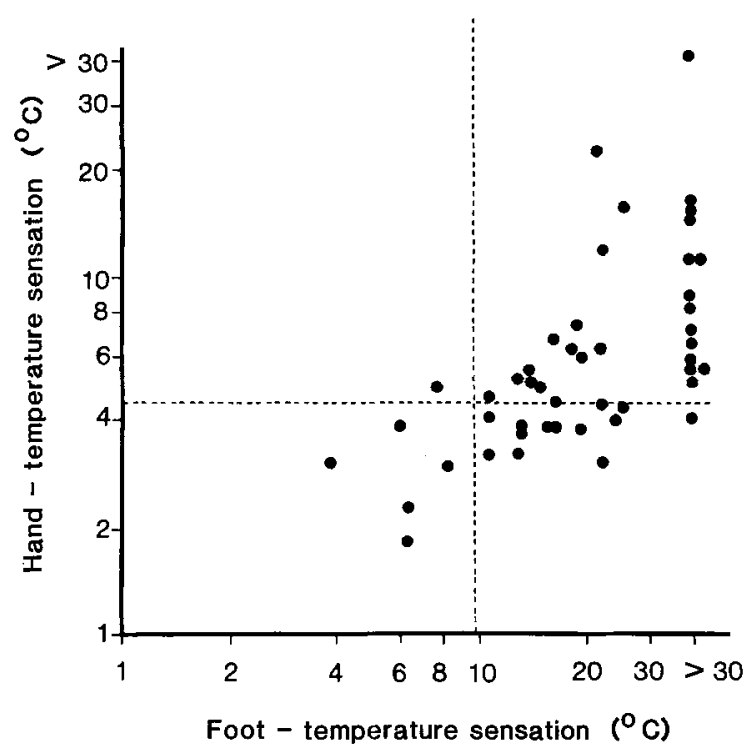

Fig. 4. Hand and foot temperature sensation $(r=0.66, p<0.001)$. The dotted lines show the upper $95 \%$ confidence limits for control subjects. Results from neuropathic subjects are shown, but not those from non-diabetic control subjects

inant: $6.3^{\circ} \mathrm{C} \quad\left(3.9-10.2^{\circ} \mathrm{C}\right)$; non-dominant: $6.3^{\circ} \mathrm{C}$ $\left(4.1-9.9^{\circ} \mathrm{C}\right)$. The reproducibility of the method is shown in Figure 2.

Thermal sensitivity in diabetic patients. Thermal sensitivity in feet and hands for the four groups of diabetic patients is shown in Figure 3. There was striking loss of thermal sensation in all feet (Fig. 3A) with neuropathic ulceration and Charcot joints, and in 11 of 22 patients thermal sensitivity was beyond the range of detection by this method and therefore more than threefold above the upper limit of normal.

Results in those with painful neuropathy covered a very wide range from normal (five patients) to a full range of abnormalities (ten patients). All but one of those ten patients with autonomic neuropathy had an abnormal thermal sensation in the foot.

Examination of the hands (Fig.3B) in the same groups led to similar conclusions, though thermal sensitivity in the hands could, in some patients, be normal in the presence of abnormalities in the feet. The relationship between thermal sensitivity of hands and feet is shown in Figure 4. All except one of the 15 patients with gross impairment of the lateral foot (sensitivity $>30^{\circ} \mathrm{C}$ ) showed a defect in the hand.

\section{Vibration sensation}

The mean perception threshold at the dominant index finger on the 48 control subjects was 3.9 volts (2.4-6.3 volts) and was the same as that on their nondominant side, which was 3.7 volts (2.4-5.6 volts). This site was more sensitive than the big toe, where the results for the dominant and non-dominant sides were the same at 5.6 volts (3.1-10.3 volts).

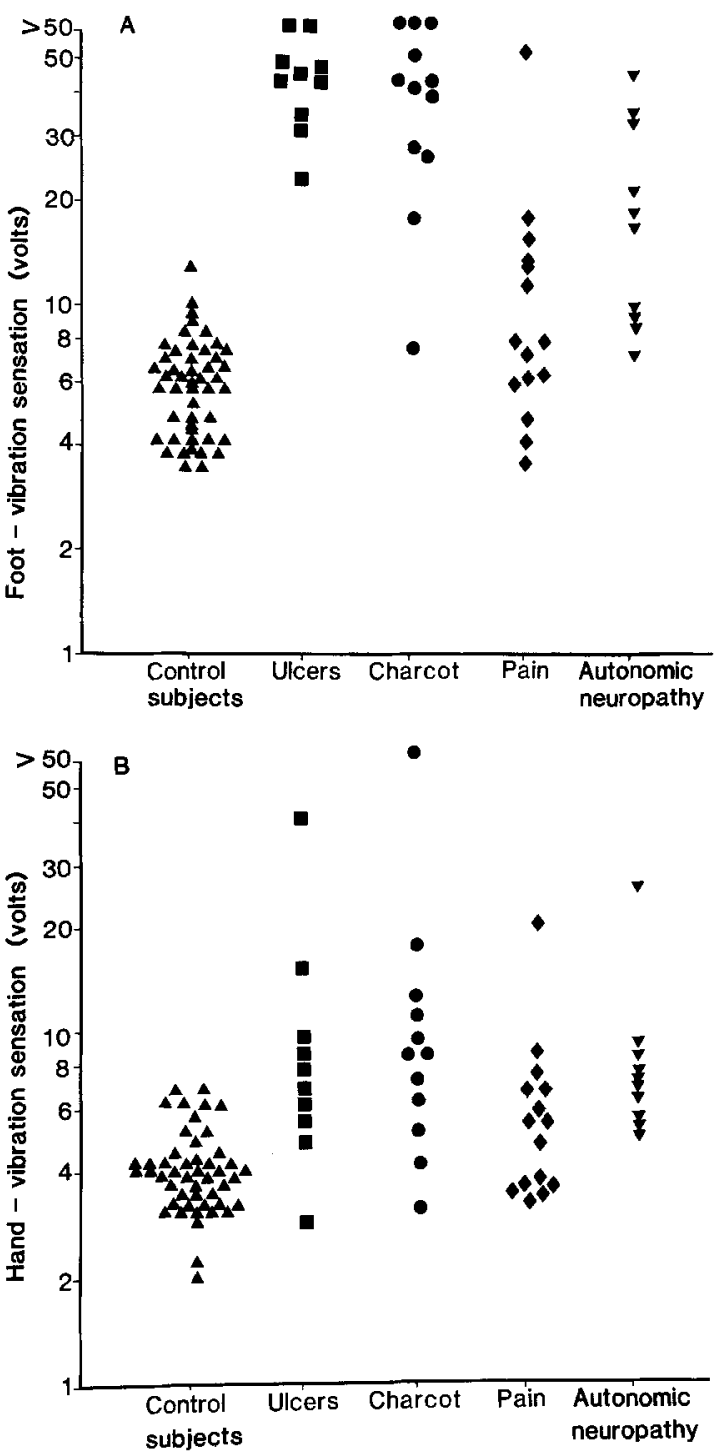

Fig.5. A Foot vibration sensation in non-diabetic control subjects and four groups of neuropathic patients. All neuropathic groups are significantly different from control subjects $(p<0.001$ for all groups except painful neuropathy, $p<0.05$ ). (Mean levels and ranges are not shown because many of the results were beyond the limits of the test). B Hand vibration sensation: Control subjects, mean 3.9 volts (2.4-6.3 volts); ulcers, 7.8 volts (1.9-32.3 volts); Charcot's, 8.6 volts (2.0-36.9 volts); painful neuropathy, 5.2 volts (2.1-13.0 volts); autonomic neuropathy, 7.3 volts (2.9-18.2 volts). All neuropathic patients were significantly different from control subjects $(p<0.001$ except for painful neuropathy, $p<0.05$ )

Vibration perception thresholds performed twice in 18 normal subjects and in 20 patients with neuropathy less than one month apart showed no significant difference, with a good correlation coefficient for normal hands $(r=0.83, p<0.01)$ and normal feet $(r=0.86$, $p<0.01)$ as well as neuropathic hands $(r=0.73, p<$ $0.01)$ and neuropathic feet $(r=0.91, p<0.01)$. Standards for normal subjects, their satisfactory reproducibility and relationship to age have been described elsewhere [21, 22]. 


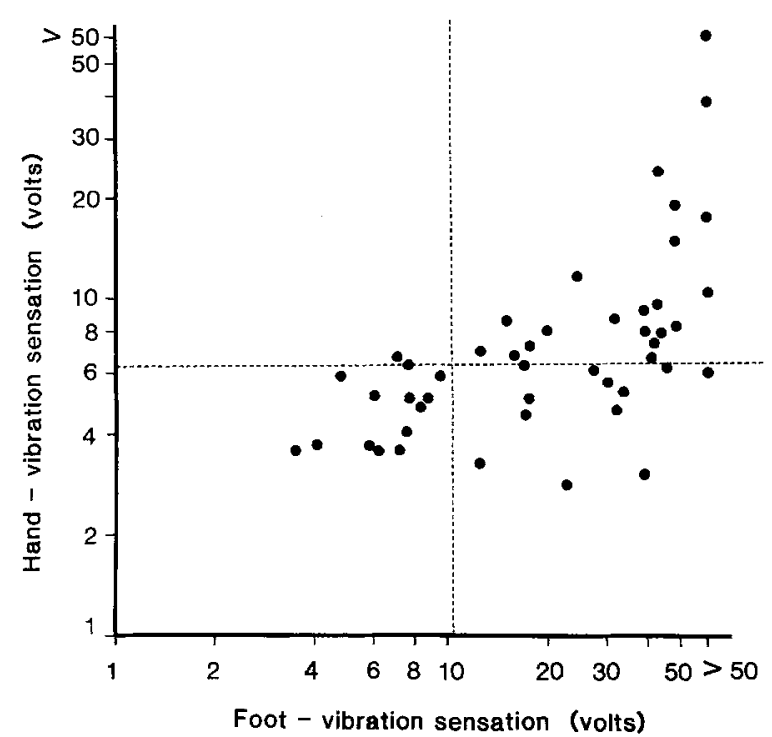

Fig. 6. Hand and foot vibration sensation $(r=0.68, p<0.001)$. The dotted lines show the upper $95 \%$ confidence limits for control subjects. Results from neuropathic subjects are shown, but not those from non-diabetic control subjects

\section{Vibration sensitivity in diabetic patients}

The resusults of vibration perception for feet and hands are shown in Figure 5. Again there was considerable impairment of vibration sensation in the feet (Fig. 5A) of those with either ulceration or Charcot joints. All but one were abnormal, five patients being outside the range of the instrument and more than five times greater than normal. Autonomic neuropathy and painful neuropathy cases ranged from normal to abnormal.

Deficits in the hands (Fig. 5B) were not as marked with only two patients having a threshold five times normal. Abnormalities were present in nearly $60 \%$ of all groups except those with pain, where only $20 \%$ were abnormal.

The majority of cases were either abnormal in both hands and feet $(21 / 47)$ or normal in both (13/47). Foot abnormalities occurred by themselves in 12 but only one had an abnormal hand result and a normal foot result (Fig. 6).

\section{Comparison of thermal and vibration sensation in diabetes}

Whilst thermal sensitivity can be impaired, sometimes severely, in the presence of normal vibration sensation (eight patients, Fig.7A), the converse was never seen in the foot and infrequently and slightly in the hands (Fig. 7B). In most cases thermal and vibration sensation were either both normal or both impaired.

\section{Autonomic function tests}

Heart rate variability (HRV) is normally greater than 12 beats/min. All those patients with an autonomic neuropathy or Charcot joints had severely impaired heart rate variation on deep breathing, the mean being
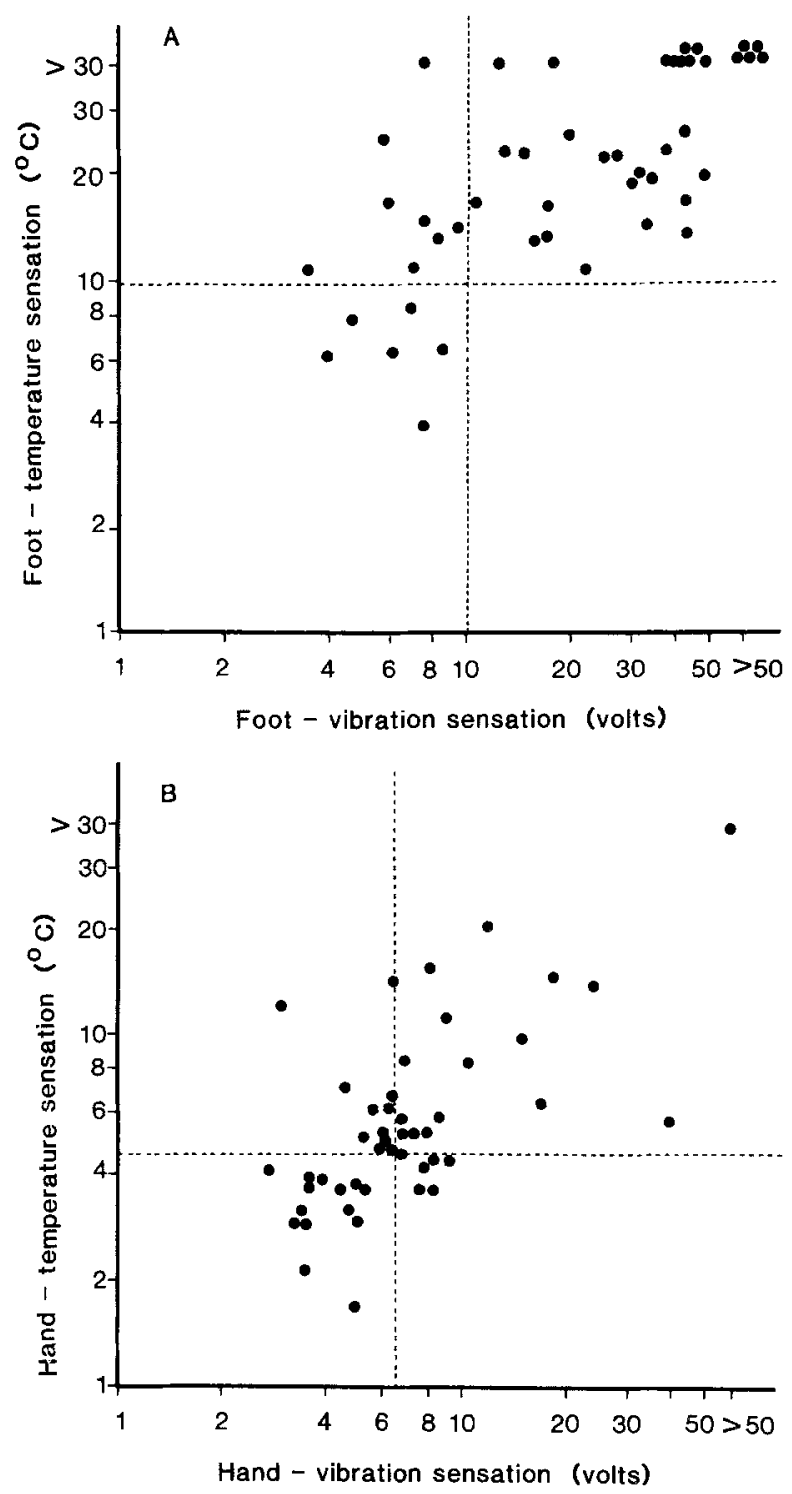

Fig.7. A Foot temperature and vibration sensation $(r=0.68$, $p<0.001$ ). There were no subjects with abnormal vibration but normal temperature sensation compared with eight subjects with normal vibration and abnormal temperature sensation. B Hand temperature and vibration sensation $(r=0.61, p<0.001)$. There were only five subjects with abnormal vibration and normal temperature sensation compared with 11 subjects with normal vibration and abnormal temperature sensation. The dotted lines shown the upper $95 \%$ confidence limits for control subjects. Results from neuropathic subjects are shown but not those from non-diabetic control subjects

the same for both groups at 3.7 beats/min (range $0-7.0$ beats $/ \mathrm{min}$ ). The mean result for those with neuropathic ulceration was 6.2 beats $/ \mathrm{min}$ (range $0-14$ beats/ min) with $80 \%<12.0$ beats $/ \mathrm{min}$. Of the 15 patients with painful neuropathy, nine had a normal response, six abnormal, with an overall mean of 12.7 beats/min (range $5-25$ beats/min.).

\section{Comparison of thermal sensation and $H R V$}

When thermal sensation in the feet was compared with HRV, an abnormal or borderline HRV ( $\leqslant 12$ beats/ min) was nearly always accompanied by impaired ther- 
mal sensation $\left(>9.8^{\circ} \mathrm{C}\right)(34$ with only four exceptions), although thermal sensation was sometimes abnormal $\left(>9.8^{\circ} \mathrm{C}\right)$ in the presence of a normal HRV (seven patients), suggesting that the long, small fibres to the foot deteriorate demonstrably before those of the Vagus nerve. In the hand an abnormal HRV was often associated with abnormal thermal sensation ( 25 patients) but this was not always the case - in 13 patients thermal sensation was normal, suggesting that vagal degeneration occurs before thermal sensation declines in the hands. In the hand, unlike the situation in the foot, there were no patients with abnormal thermal sensation and a normal HRV.

\section{Skin temperature}

Mean \pm SD skin temperature for the 45 control subjects was $31.8 \pm 2.8^{\circ} \mathrm{C}$ at the index finger and $28.2 \pm 3.7^{\circ} \mathrm{C}$ at the big toe and was similar to that in the 43 diabetic subjects $\left(30.6 \pm 3.4^{\circ} \mathrm{C}\right.$ in the hand; $28.7 \pm 3.8^{\circ} \mathrm{C}$ in the foot).

\section{Discussion}

Thermal sensory measurement is simple and reproducible, and provides a quantitative assessment of small nerve fibre function. The hand is more sensitive than the foot and there is some reduction of sensitivity with age, especially in the hand. The best sites for measurement are the thenar eminence of the hand and the lateral aspect of the foot. The results are symmetrical and there is no difference between dominant and non-dominant sides.

Thermal sensitivity is always grossly abnormal in the feet of diabetic subjects with neuropathic ulceration and Charcot joints, and frequently beyond the limits of detection of the apparatus. This degree of severity represents an inability to detect temperature changes between $15^{\circ} \mathrm{C}$ and $45^{\circ} \mathrm{C}$ and is more than three times the limits found in normal subjects. Diabetic patients with predominantly autonomic neuropathy (also a small fibre modality) generally show gross thermal sensory loss, while the whole range of values from normal to grossly abnormal are found in those with painful neuropathy. Measurement of vibration perception thresholds leads to similar conclusions.

Comparison of thermal sensory (small fibre) defects with those of vibration perception threshold (large fibre) suggests that small fibres are more susceptible to damage. Thus in some cases, especially those with painful neuropathy, severe thermal sensory loss is found in the presence of intact vibration perception, whereas the converse does not occur. More commonly, however, both modalities are impaired indicating that diabetes usually damages both kinds of fibres. The demonstration that the small fibres are always affected in diabetic neuropathy is in accordance with clinical observations. It was predicted by Lawrence [12], and accounts for the autonomic involvement which is characteristic of diabetic neuropathy. Sympathetic defects (small fibre) are responsible for the loss of vasomotor tone and increase in peripheral blood flow now established as a feature of diabetic neuropathy, including painful neuropathy [13-15]. There are, too, some cases, perhaps as many as $10 \%$, in which small fibre defects are predominant and in which there is an association of autonomic failure with loss of thermal and pain sensation (linked with Charcot joints) but intact large fibre modalities $[16,17]$. Direct recordings of sympathetic activity are also more frequently deficient in diabetes than in other neuropathies [18]. Finally we have ourselves observed that autonomic damage is present in almost every case with foot ulceration and may be necessary for their development.

Painful neuropathies in diabetes form a distinct group with characteristic and reversible symptoms. The clinical and electrophysiological findings correlate poorly with the severity of the pains and can be shown to range from normal to severely abnormal $[1,2]$. Thermal and vibration sensory changes lead to the same conclusions and emphasise that the pain occurs independently of conventional neurological impairment. Its cause is unkown, although there appears to be an interesting relationship with small fibre injury or regeneration $[1,2,19]$, and striking similarity to sympathetic disorders such as causalgia.

Diabetic neuropathy rarely causes symptoms in the hands and fingers. However the present investigations show that sensory impairment is frequently detectable in the hands. As in the feet, thermal sensitivity is more often defective than vibration perception. These observations confirm the 'stocking and glove' distribution of diabetic neuropathy. The hands are less frequently and less severely affected which may simply be a function of nerve length [20]. The present investigation also suggests that thermal sensation in the feet is impaired before the vagus, which in turn is demonstrably damaged before thermal impairment in the hands. Measurement of sensory potential amplitudes has previously shown that the nerves of the feet are more frequently affected than those in the hands, and that distal portions of sensory nerves are affected before proximal damage occurs [3-5].

Impairment of thermal sensitivity is the rule in diabetic neuropathy, with the exception of some cases of painful neuropathy. Its measurement is simple and reproducible and will be of great value in the long-term assessment of the natural history of diabetic neuropathy, or the alteration of its course by therapeutic intervention. When damage is very severe in the feet, the hands are also affected. Thermal sensitivity is in some cases selectively impaired when compared with vibration perception, suggesting that small fibres are more prone to damage in diabetic neuropathy.

Acknowledgements. We thank Dr. D. A. Pyke and Professor C. D. Marsden for their help and encouragement. R.J.C.G. is supported by Pfizer, Sandwich, Kent, UK. 


\section{References}

1. Brown MJ, Martin JR, Asbury AK (1976) Painful diabetic neuropathy: a morphometric study. Arch Neurol 33: 164-171

2. Archer AG, Watkins PJ, Thomas PK, Sharma AK, Payan J (1983) The natural history of acute painful neuropathy in diabetes mellitus. J Neurol Neurosurg Psychiatry 46: 491-499

3. Lamontagne A, Buchthal F (1970) Electrophysiological studies in diabetic neuropathy. J Neurol Neurosurg Psychiatry 33: 442-452

4. Noël $P(1973)$ Sensory nerve conduction in the upper limbs at various stages in diabetic neuropathy. J Neurol Neurosurg Psychiatry 36: 786-796

5. Gupta PR, Dorfman LJ (1981) Spinal somatosensory conduction in diabetes. Neurology (NY) 31:841-845

6. Dyck PJ, Zimmerman IR, O'Brien PC, Ness A, Caskey PE, Karnes J, Bushek W (1978) Introduction of automated systems to evaluate touch-pressure, vibration, and thermal cutaneous sensation in man. Ann Neurol 4: 502-510

7. Lindblom U (1981) Quantitative testing of sensibility including pain. In: Stâlberg E, Young RR (eds) Neurology, Vol 1. Clinical Neurophysiology. Butterworth, London, pp 168-190

8. Boulton AJM, Hardisty CA, Betts RP, Franks CI, Worth RC, Ward JD, Duckworth T (1983) Dynamic foot pressure and other studies as diagnostic and management aids in diabetic neuropathy. Diabetes Care 1: 26-33

9. Fruhstorfer H, Lindblom U, Schmidt WG (1976) Method for quantitive estimation of thermal thresholds in patients. J Neurol Neurosurg Psychiatry 39: 1071-1075

10. Fagius J, Wahren LK (1981) Variability of sensory threshold determinations in clinical use. J Neurol Sci 51:11-27

11. MacKay JD, Page MMcB, Cambridge J, Watkins PJ (1980) Diabetic autonomic neuropathy: the diagnostic value of heart rate monitoring. Diabetologia 18: 471-478

12. Lawrence RD (1965) The diabetic life, 17th edn. Churchill, London, $\mathrm{p} 157$
13. Edmonds ME, Roberts VC, Watkins PJ (1982) Blood flow in the diabetic neuropathic foot. Diabetologia 22: 9-15

14. Boulton AJM, Scarpello JHB, Ward JD (1982) Venous oxygenation in the diabetic foot. Diabetologia 22:6-8

15. Archer AG, Roberts VC, Watkins PJ (1984) Blood flow patterns in painful diabetic neuropathy. Diabetologia 27: 563-567

16. Brown MJ, Ashbury AK (1984) Diabetic neuropathy. Ann Neurol 15:2-12

17. Said G, Slama G, Selva J (1983) Progressive centripetal degeneration of axons in small fibre diabetic polyneuropathy. Brain 106: 791-807

18. Fagius $\mathbf{J}$ (1982) Microneurographic findings in diabetic polyneuropathy with special reference to sympathetic nerve activity. Diabetologia $23: 415-420$

19. Dyck PJ, Lambert EH, O'Brien PC (1976) Pain in peripheral neuropathy related to rate and kind of fiber degeneration. Neurology (Minneap) 26: 466-471

20. Waxman SG (1980) Pathophysiology of nerve conduction: relation to diabetic neuropathy. Ann Intern Med 92: 297-301

21. Bloom S, Till S, Sönksen P, Smith S (1984) Use of a biothesiometer to measure individual vibration thresholds and their variation in 519 non-diabetic subjects. Br Med J 288: 1793-95

22. Steiness IB (1957) Vibration perception in normal subjects: a biothesiometric study. Acta Med Scand 158: 315-325

Received: 27 July 1984

and in revised form: 11 December 1984

Dr. P.J. Watkins

Diabetic Department

King's College Hospital

Denmark Hill

London SE5 9RS

UK 